\title{
Puerperal Group A Streptococcal sepsis: a case report
}

\author{
Nithya $\mathbf{J} .{ }^{1 *}$, Sathyamurthy $\mathbf{G}^{.}{ }^{2}$, Balavinoth $\mathbf{R}^{3}$
}

\author{
${ }^{1}$ Department of Obstetrics and Gynaecology, GKNM Hospital, Coimbatore, Tamil Nadu, India \\ ${ }^{2}$ Division of Critical Care Medicine, GKNM Hospital, Coimbatore, Tamil Nadu, India \\ ${ }^{3}$ Division of Infectious diseases, GKNM Hospital, Coimbatore, Tamil Nadu, India
}

Received: 26 September 2021

Revised: 25 October 2021

Accepted: 26 October 2021

\section{*Correspondence:}

Nithya J.,

E-mail: nithya.ms2010@gmail.com

Copyright: (c) the author(s), publisher and licensee Medip Academy. This is an open-access article distributed under the terms of the Creative Commons Attribution Non-Commercial License, which permits unrestricted non-commercial use, distribution, and reproduction in any medium, provided the original work is properly cited.

\begin{abstract}
Group A Streptococcal (GAS) sepsis in puerperium is one of the recognised causes of maternal mortality. Though the onset is often insidious, it can progress rapidly to a life-threatening invasive infection, toxin-mediated shock, and endorgan failure, even before clinical signs become apparent. We report a case of puerperal GAS sepsis that was successfully managed. 24-years-old para 1 was readmitted to the intensive care unit requiring non-invasive ventilation on postnatal day 6 with clinical and biochemical features of sepsis. Blood culture, episiotomy wound swab, and high vaginal swab grew GAS. Broad-spectrum antibiotics initiated. She developed ascites that progressively increased and needed therapeutic paracentesis. She was discharged after four weeks of hospitalization. Early identification and prompt treatment are the keys to prevent severe morbidity and maternal mortality.
\end{abstract}

Keywords: Group A Streptococci infection, Toxic shock syndrome, Puerperal sepsis

\section{INTRODUCTION}

Group A streptococcal (GAS) infection in puerperium is one of the recognised causes of maternal mortality. Postpartum women have a 20 -fold increased incidence of invasive GAS compared with non-pregnant women. ${ }^{1}$ The WHO reports the prevalence of puerperal sepsis in live births as $4.4 \% .^{2}$ Most of the pregnancy-associated GAS infections are community-acquired with $15-25 \%$ being nosocomial. ${ }^{3}$ Increased susceptibility to GAS could be due to compromised mucosal or cutaneous barrier, change in vaginal $\mathrm{pH}$, or suppressed innate immunity. ${ }^{4}$ The incidence of invasive GAS infections is now estimated to be about 2-4 cases per 1,00,000 population every year in developed countries. ${ }^{5}$ The HPA survey confirmed the rapid mortality associated with these infections, with $20 \%$ of women dying within 7 days of diagnosis. ${ }^{6}$

We report a case of puerperal GAS sepsis that was successfully managed in our institute.

\section{CASE REPORT}

A 24 years para1 presented to the emergency department on postnatal day 6 with intermittent high-grade fever, breathlessness, chest discomfort, and vaginal discharge for 1 day. She was referred to our institute at 34 weeks in view of oligohydramnios. She was diagnosed with gestational diabetes and initiated on oral hypoglycemic agents. She was on strict antepartum surveillance and labour was induced at 38 weeks in view of gestational diabetes with oligohydramnios. Intrapartum period was uneventful and she delivered vaginally. Postnatal blood sugars were normal.

At the emergency room, she was conscious, oriented, pale with bilateral pitting pedal edema, pulse rate: 142/min, blood pressure: $100 / 60 \mathrm{mmHg}$, temperature: $99.3^{\circ} \mathrm{F}$, respiratory rate: $35 / \mathrm{min}$, saturation: $98 \%$ on room air. Cardiovascular and respiratory system unremarkable. The 
abdomen was soft, there was minimal distension and the uterus was non-tender.

Local examination revealed episiotomy wound gaping, foul-smelling lochia. A high vaginal swab and wound swab was taken and sent for culture and sensitivity. In view of clinical impression of sepsis, blood culture, procalcitonin, lactate, complete blood count, renal function test, liver function test, coagulation profile sent. She was started on meropenem, shifted to the Intensive care unit, and started on Non-invasive ventilation (NIV).

Bedside ultrasound showed no pelvic or endometrial collection. Investigations showed haemoglobin- $8.2 \mathrm{~g} / \mathrm{dl}$, Packed cell volume (HCT)- 25.7\%, total WBC count $64.0 \times 10^{3} / \mathrm{ul}$, polymorphs- $80 \%$; serum procalcitonin- 8.12 $\mathrm{ng} / \mathrm{ml}$, serum urea- $15 \mathrm{mg} / \mathrm{dl}$, serum creatinine $0.7 \mathrm{mg} / \mathrm{dl}$, serum lactate $52.0 \mathrm{mg} / \mathrm{dl}$, liver function showed total bilirubin- $1.6 \mathrm{mg} / \mathrm{dl}$, direct bilirubin- $0.6 \mathrm{mg} / \mathrm{dl}$, indirect bilirubin- $1 \mathrm{mg} / \mathrm{dl}$, SGOT- $32 \mathrm{u} / \mathrm{l}$, SGPT- $8 \mathrm{u} / \mathrm{l}$, total protein- $4.6 \mathrm{~g} / \mathrm{dl}$, albumin- $1.7 \mathrm{~g} / \mathrm{dl}$; serum electrolytes: sodium $130 \mathrm{mmol} / \mathrm{l}$, potassium $4.0 \mathrm{mmol} / \mathrm{l}$, chloride 101 $\mathrm{mmol} / \mathrm{l}$, bicarbonate $18.1 \mathrm{mmol} / \mathrm{l}$. Prothrombin time 18.5 sec, INR 1.63, activated partial thromboplastin time 37.6 sec. 12 hours after hospitalisation she developed uterine tenderness. She was started on thromboprophylaxis. Blood culture grew GAS and the antibiotic was deescalated to penicillins. The infection control team was notified.

On day 2 of admission, she developed gross abdominal distension, absent bowel sounds. Contrast-enhanced computerized tomogram (CECT) abdomen and pelvis showed features of paralytic ileus, grossly distended stomach, moderate ascites with no endometrial collection (Figure 1 and 2). The surgeon advised conservative management. She had recurrent episodes of loose stools, stool microscopic examination was normal. Clindamycin was added as an anti-exotoxin cover. Vaginal and wound swabs also grew GAS. She was weaned off NIV and continued on supportive care. She was shifted to ward on day 4 of hospitalisation.

She was continued on parenteral antibiotics. On day 8 of hospitalisation, she developed increasing abdominal distension. Ultrasonography showed ascites. Ascites tapping done, $400 \mathrm{ml}$ fluid drained and sent for the examination. Ascitic fluid- glucose- $50 \mathrm{mg} / \mathrm{dl}$, protein- 3 g/dl (exudate), ADA- $22 \mathrm{u} / \mathrm{l}$. Total count- 8,280 cells/cu.mm, polymorphs- $86 \%$, lymphocytes- 14 . Gram stain- pus cells seen. Organism not seen. She continued to have febrile spikes. In view of a possible secondary infection due to gram-negative bacilli, the antibiotic was switched to piperacillin-tazobactum after sending blood culture which was later found to be sterile. Fever settled.1 unit-packed red blood cell was given on day 11 of admission in view of moderate anemia ( $\mathrm{Hb}-7.6 \mathrm{~g} / \mathrm{dl})$.

On day 21 of hospitalisation, CT abdomen and pelvis showed a large loculated collection with smooth enhancing walls, peritoneal thickening, and enhancement in the pelvis with a normal postpartum uterus (Figure 3 and 4). A pigtail catheter was inserted and serous fluid of 2100 $\mathrm{ml}$ was drained. It was sent for culture and sensitivity and showed no growth. The catheter was removed on day 4 of insertion when the drain was nil. Repeat ultrasound showed a loculated collection of $100 \mathrm{ml}$. Antibiotics were stopped as she improved clinically and had negative cultures. Her counts were serially monitored and it decreased from 73,000 at admission to 11,000 at discharge on day 28 (Figure 5). Her serum procalcitonin level was less than 0.05 at discharge.

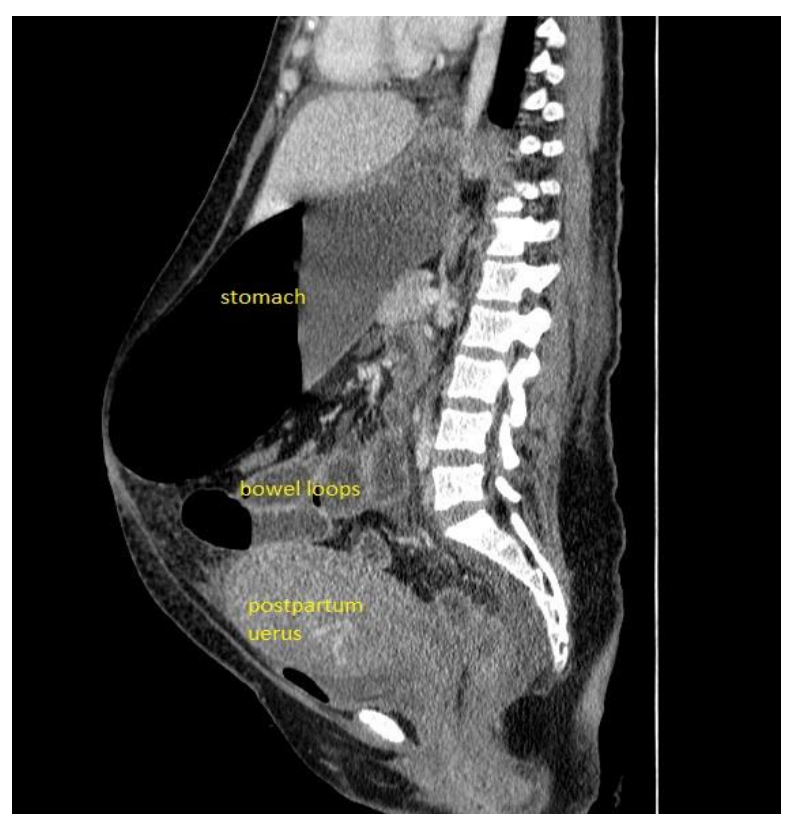

Figure 1: Contrast-enhanced computerized tomogram (CECT) abdomen and pelvis sagittal section with, grossly distended stomach, dilated bowel loops with no endometrial collection.

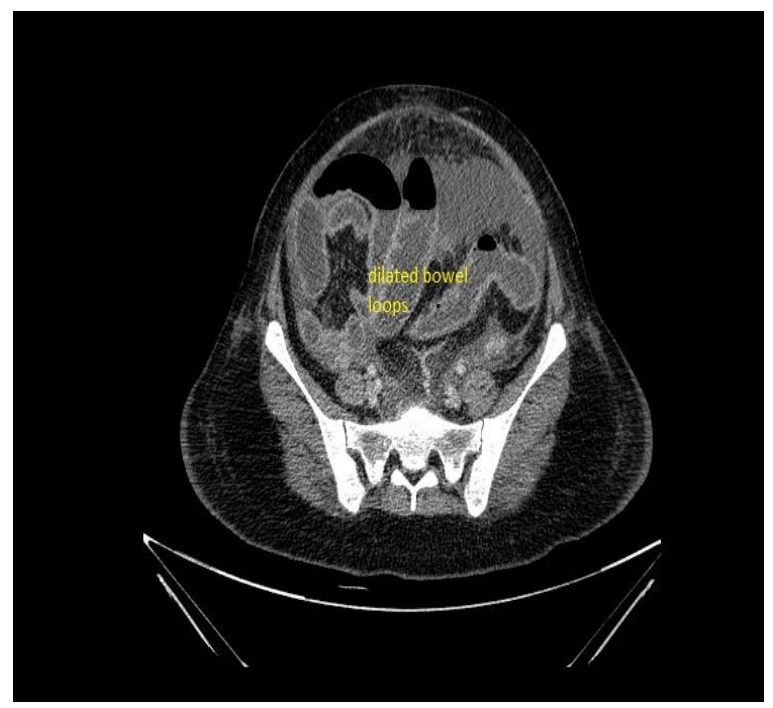

Figure 2: CECT abdomen and pelvis axial section with dilated bowel loops. 


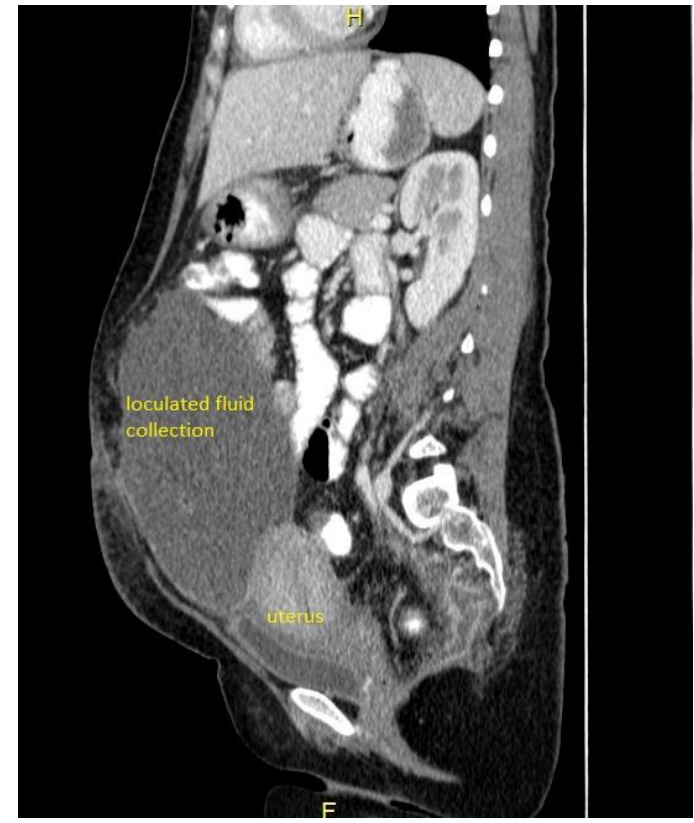

Figure 3: CT abdomen and pelvis sagittal section with a large loculated collection with smooth enhancing walls with a normal postpartum uterus.

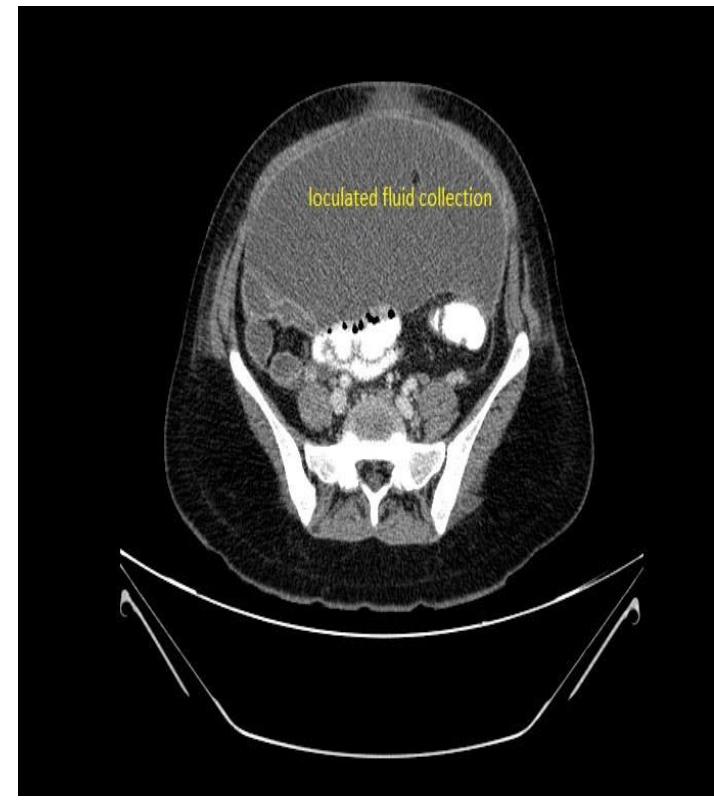

Figure 4: CT abdomen and pelvis axial section with a large loculated collection with smooth enhancing walls.

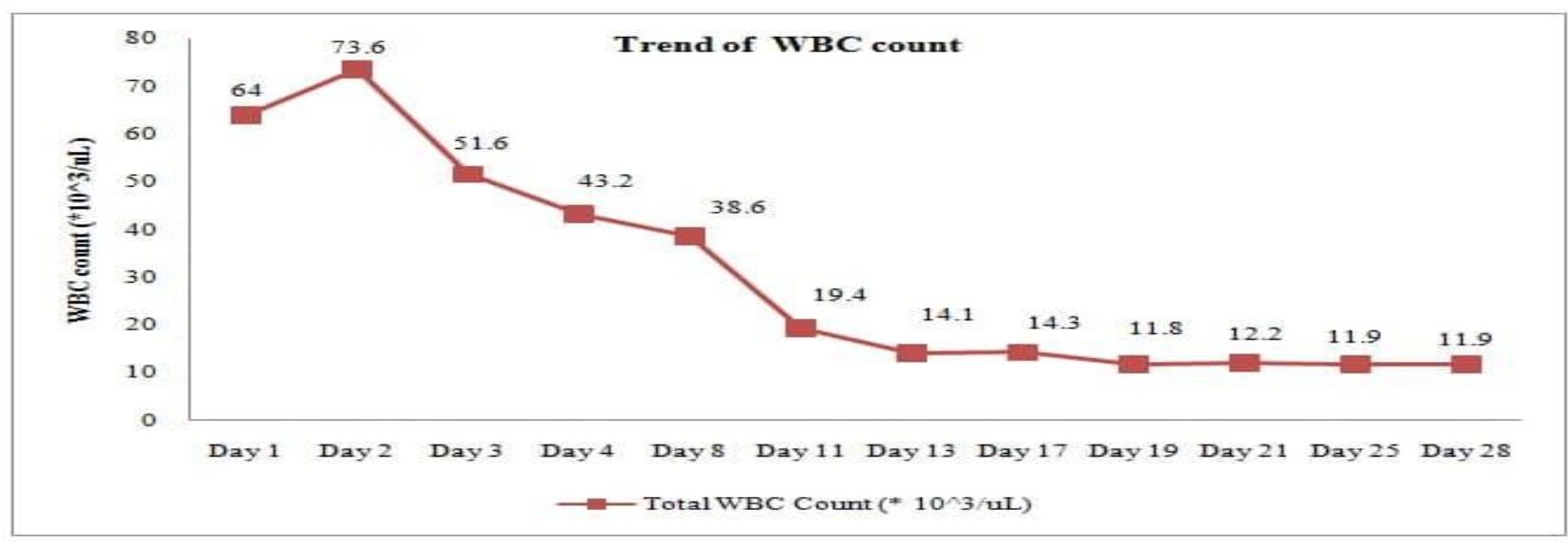

Figure 5: Trend of WBC count.

\section{DISCUSSION}

In the past, puerperal GAS infections have been associated with health care workers. In this antibiotic era, there is a resurgence of GAS infection in the puerperium. The cause for this is not exactly known.

GAS ( $\beta$-haemolytic streptococcus pyogenes), a grampositive coccus is commensal in the skin and throat. About $5-30 \%$ of the population are asymptomatic carriers. Transmission occurs from person to person, through the respiratory droplet, or contact with secretions. GAS is rarely present in the normal vaginal flora and can be rapidly fatal in pregnancy and puerperium. The confidential enquiries into maternal deaths found an association between a recent history of sore throat in either the mother or a family member and the development of
GAS-positive puerperal sepsis. Organisms may be transferred from the throat or nose via hands to the perineum. Post-delivery vaginal bacteria may ascend into the uterus. Blood and necrotic decidual tissue act as excellent growth media for multiplication. $85 \%$ of GAS occurs postpartum, most after vaginal delivery and occurring within the first 4 days postpartum. ${ }^{7}$

Noninvasive GAS (pharyngitis, scarlet fever, impetigo) accounts for approximately $40 \%$ of GAS cases. ${ }^{8}$ Clinically, Invasive GAS (iGAS) includes invasion of blood or deep tissue and has the potential to cause lifethreatening conditions such as postpartum endometritis, streptococcal toxic shock syndrome, necrotizing fasciitis, and rapidly progressive septicemia and death. iGAS infection produces symptoms usually within 2 to 3 days post-delivery. ${ }^{8}$ Fever with chills from resultant bacteremia 
is common. $75 \%$ of postpartum women with iGAS have either endometritis or infection without identifiable focus. ${ }^{9}$ Signs and symptoms of GAS endometritis may be mild and present with nonspecific symptoms like fever, chills, nausea, vomiting, and myalgias. Uterine or pelvic tenderness does not correlate with the severity of the infection. Systemic complications may develop if not promptly identified and treated. Sepsis caused by GAS can progress to shock and multiorgan failure within 48 to 96 hours. ${ }^{10}$ iGAS is associated with a significant mortality rate of 15 to $20 \% .^{11}$ Streptococcal TSS complicates approximately $6 \%$ of invasive GAS in adults. ${ }^{3}$ A massive inflammatory response occurs secondary to antigen release by host lymphocytes. This is associated with a case fatality rate of approximately $50 \% .^{12}$

Physiological changes in pregnancy may mask the signs and symptoms of sepsis. Hence a detailed history and a high index of suspicion are necessary to recognise sepsis in pregnancy. The CMACE report has identified the presence of tachypnoea, neutropenia, and hypothermia as the most ominous signs. ${ }^{13}$ Diarrhoea is one of the commonest symptoms of pelvic sepsis. Early warning scores help in the identification of critically ill patients.

Baseline blood tests such as full blood count, coagulation profile, renal function tests, and C-reactive protein should be sent at presentation. Other samples guided by clinical suspicion of the focus of infection (throat swabs, midstream urine, high vaginal swab, wound swab, breast milk, stool, epidural site or CSF, swabs from baby) should be obtained ideally before starting antibiotic therapy. Radiological investigations (ultrasound scan, CT, and MRI of the abdomen and pelvis) should be considered if the clinical presentation suggests intra-abdominal pathology or if there is an inadequate response to therapy.

Pregnancy-specific sepsis bundles take into consideration physiological variables of pregnancy. Clinicians should have a high index of suspicion to recognise early, perform essential investigations and monitor (cultures, blood lactate, and hourly urine output), and commence essential treatment (oxygen, intravenous fluids, and antibiotics)'the sepsis six'.14 The primary goal is to maintain oxygenation and perfusion of vital organs while identifying and treating infection. Survival has been shown to be improved by using the surviving sepsis campaign guidance and initiated in the first hour of diagnosis. ${ }^{15}$ Key recommendations includes- (i) antibiotics; (ii) maintain oxygen saturation >94\%; (iii) fluid resuscitation; (iv) Maintain mean arterial pressure (MAP) of $65 \mathrm{mmHg}$; (v) maintain haemoglobin at 70-90 g/l; (vi) monitoring and correction of coagulopathy; (vii) early advice from an infectious disease physician or microbiologist should be sought; and (viii) controlling the source of infection and it may require both medical and surgical intervention.

When the patient is septic, consider piperacillintazobactam or meropenem. For GAS infection, clindamycin is more effective than penicillin. For GAS toxic shock syndrome, intravenous penicillin G 24 million units/day in divided doses with intravenous clindamycin $900 \mathrm{mg} \mathrm{q} 8 \mathrm{~h}$ is necessary to turn off toxin production. The addition of clindamycin is associated with survival benefits in GAS infections. ${ }^{16}$ A surgical focus of infection should be drained promptly after antibiotics initiation. If myometrial necrosis is the source of infection, consider hysterectomy. The culture and bacterial sensitivities of infected tissue should be performed to guide antibiotic therapy. Non-steroidal anti-inflammatory drugs should not be used in septic patients as it may mask the presentation of invasive streptococcal infection, leading to delay in intervention.

\section{CONCLUSION}

Knowledge regarding GAS infections is of paramount importance to the obstetrician. A high index of suspicion is needed because of the varied and atypical presentation. Delay in the diagnosis of invasive GAS can have disastrous consequences including mortality. The mainstay of management is supportive with resuscitation and source control playing a significant role. Education of health care professionals and patients regarding the most basic aspects of hygiene and disease is needed to reduce morbidity and mortality.

\section{Funding: No funding sources \\ Conflict of interest: None declared \\ Ethical approval: Not required}

\section{REFERENCES}

1. Rimawi BH, Soper DE, Eschenbach DA. Group A streptococcal infections in obstetrics and gynecology. Clin Obstet Gynecol. 2012;55(4):864-74.

2. Bonet M, Oladapo OT, Khan DN, Mathai M, Gülmezoglu AM. New WHO guidance on prevention and treatment of maternal peripartum infections. Lancet Glob Health. 2015;3(11):667-8.

3. Bonet $\mathrm{M}$, Oladapo OT, Khan DN, Mathai M, Gülmezoglu AM. New WHO guidance on prevention and treatment of maternal peripartum infections. Lancet Glob Health. 2015;3(11):667-8.

4. Hamilton SM, Stevens DL, Bryant AE. Pregnancyrelated group A streptococcal infections: temporal relationships between bacterial acquisition, infection onset, clinical findings, and outcome. Clin Infect Dis. 2013;57:870-6.

5. Steer AC, Lamagni T, Curtis N, Carapetis JR. Invasive group a streptococcal disease: epidemiology, pathogenesis and management. Drugs. 2012;72(9):1213-27.

6. Palaniappan N, Menezes M, Willson P. Group A streptococcal puerperal sepsis: management and prevention. Obstet Gynaecol. 2012;14:9-16.

7. Chuang I, Van BC, Beall B, Schuchat A. Populationbased surveillance for postpartum invasive group a streptococcus infections, 1995-2000. Clin Infect Dis. 2002;35(6):665-70. 
8. Olp RJ, Chamales IA, Schmiedecke SS. A Case Study of Puerperal Group A Streptococcal Infection Complicated by Toxic Shock Syndrome. AJP Rep. 2020;10(1):1-4.

9. Deutscher M, Lewis M, Zell ER, Taylor TH, Van BC, Schrag S, et al. Incidence and severity of invasive Streptococcus pneumoniae, group A Streptococcus, and group B Streptococcus infections among pregnant and postpartum women. Clin Infect Dis. 2011;53:11423.

10. Soper DE. Early recognition of serious infections in obstetrics and gynecology. Clin Obstet Gynecol. 2012;55(04):858-63.

11. Phupong V, Lersbuasin P, Kengsakul M, Lertkhachonsuk R. Invasive group A streptococcal infection in postpartum period mimics hypovolaemic shock. J Obstet Gynaecol. 2016;36(3):283-4.

12. Loughlin RE, Roberson A, Cieslak PR, Lynfield R, Gershman K, Craig A, et al. Active Bacterial Core Surveillance Team.The epidemiology of invasive group A streptococcal infection and potential vaccine implications: the United States, 2000-2004. Clin Infect Dis. 2007;45(7):853-62.
13. Cantwell R, Brock T, Cooper G, Dawson A, Drife J, Garrod D, et al. Saving Mothers' Lives: Reviewing maternal deaths to make motherhood safer: 20062008. The Eighth Report of the Confidential Enquiries into Maternal Deaths in the United Kingdom. BJOG. 2011;118(1):1-203.

14. Greer O, Shah NM, Johnson MR. Maternal sepsis update: current management and controversies. Obstet Gynaecol. 2020;22:45-55

15. Elton RJ, Chaudhari S, Sepsis in obstetrics. BJA Edu. 2015;15(5):259-64.

16. Babiker A, Li X, Lai YL, Strich JR, Warner S, Sarzynski S, et al. Effectiveness of adjunctive clindamycin in $\beta$-lactam antibiotic-treated patients with invasive $\beta$-haemolytic streptococcal infections in US hospitals: a retrospective multicentre cohort study. Lancet Infect Dis. 2021;21(5):697-710.

Cite this article as: Nithya J, Sathyamurthy G, Balavinoth R. Puerperal group A streptococcal sepsis: a case report. Int J Reprod Contracept Obstet Gynecol 2021;10:4573-7. 